\title{
Urbanization Effect on Energy-Related Carbon Emissions in Jiangsu Province from the Perspective of Resident Consumption
}

\author{
Xinlin Zhang ${ }^{1,3-5}$, Yuan Zhao ${ }^{1-5 *}$, Xin Xu ${ }^{1,3-5}$, Changjian Wang ${ }^{6}$ \\ ${ }^{1}$ School of Geographic Science, Nanjing Normal University, Nanjing 210023, China \\ ${ }^{2}$ Ginling College, Nanjing Normal University, Nanjing 210097, China \\ ${ }^{3}$ Key Laboratory of Virtual Geographic Environment (Nanjing Normal University), \\ Ministry of Education, Nanjing, 210023, China \\ ${ }^{4}$ State Key Laboratory Cultivation Base of Geographical Environment Evolution (Jiangsu Province), \\ Nanjing, 210023, China \\ ${ }^{5}$ Jiangsu Center for Collaborative Innovation in Geographical Information Resource Development and Application, \\ Nanjing, 210023, China \\ ${ }^{6}$ Guangzhou Institute of Geography, Guangdong Open Laboratory of Geospatial Information Technology \\ and Application, Guangzhou 510070, China
}

Received: 24 December 2016

Accepted: 13 February 2017

\begin{abstract}
Controlling carbon emissions without impairing urbanization and economic development highlights the necessity of researching energy-related carbon emissions. Urban areas have become the main source of energy consumption and carbon emissions. This paper has developed a modified version of the Kaya identity, which incorporates urbanization and resident consumption, to analyze urbanization effect on carbon emissions in Jiangsu Province. Then, the Kuznets curve theory was introduced to estimate the inflection point of the marginal urbanization effect. The results indicated that the urbanization effect was still an important factor that influences total carbon emissions. The marginal urbanization effect will still increase until the urbanization rate reaches $78.94 \%$. Therefore, Jiangsu should also pay attention to the urbanization effect even though it may increase slowly or decrease, and the results of this paper on marginal urbanization effect make it clear that controlling the carbon emissions without the expense of urbanization growth and economic development is still a big challenge for Jiangsu Province. We have proposed some policy recommendations, which include paying attention to the quality of development of urbanization, adjusting the industrial structure, making changes to lifestyles, and so on.
\end{abstract}

Keywords: urbanization effect, marginal urbanization effect, carbon emissions, extended Kaya identity, Jiangsu Province

*e-mail: zhaoyuan@njnu.edu.cn 


\section{Introduction}

Global warming has become an indisputable fact, and increases in greenhouse gases will bring about disaster for humanity and the earth. The fourth report of the Intergovernmental Panel on Climate Change (IPCC) has shown that carbon dioxide accounts for about $76.7 \%$ of total greenhouse gas emissions [1], and it is the main component of greenhouse gases. This illustrates that the key to reducing greenhouse gas emissions is to control carbon emissions. At the United Nations Climate Change Conference, the Chinese government promised to cut its carbon intensity by $40-45 \%$ by 2020 with respect to 2005 levels [2]. In 2014 China made a promise to reach peak carbon emissions before 2030 in a joint statement on climate issued by China and the United States [3]. Therefore, fulfilling these emissions reduction commitments while maintaining rapid and stable socio-economic development will be an important and urgent task that also highlights the necessity of the study of energy-related carbon emissions.

With the rapid growth in global urbanization, more people have lived in urban areas than in rural areas since 2007 [4]. Besides, urban areas have also become the main source of energy consumption and carbon emissions. Urban areas account for only $2 \%$ of the world's surface area, but contribute $75 \%$ of the world's total energy consumption [4] and more than $70 \%$ of the world's carbon emissions [5]. Therefore, an increasing number of researchers have begun to pay attention to urbanization effect on carbon emissions.

According to empirical studies, urbanization influences carbon emissions through economic growth, changes in residents consumption, industrial restructuring, and various other factors [6]. For instance, urbanization leads to the agglomeration of people and economic activities, which in turn can promote increases in energy consumption and carbon emissions. In contrast, agglomeration effects and the scale effect caused by urbanization contribute to improving the efficiency of energy utilization and promote clean energy technology, which will thus contribute to control and inhibit carbon emissions. A regional urbanization effect on carbon emissions can be mainly subdivided into driving effects and inhibiting effects. Some studies have indicated that urbanization promotes carbon emissions:

- Cole and Neumayer (2004) revealed that a higher urbanization rate would increase carbon emissions using data from 86 countries for the period from 1975 to 1998 [7].

- York (2007) studied the urbanization rates and carbon emissions of 14 European Union countries, and found that urbanization led to an increase in carbon emissions during the period 1960-2025 [8].

- Wang et al. (2016) studied the relationship between urbanization, energy use, and carbon emissions within the Association of Southeast Asian Nations countries, and observed that a rise in an urban population of $1 \%$ resulted in an increase in carbon emissions of $0.20 \%$ over the period 1980-2009 [9].

- Wu et al. (2016) indicated that a higher urbanization rate would lead to an increase in carbon emissions in China before 2020 [10].

Other studies, however, have indicated that urbanization controls or limits carbon emissions:

- Fan et al. (2006) indicated that urbanization had a significant negative impact on carbon emissions in some high-income countries over the period 19752000 [11].

- Poumanyvong and Kaneko (2010) used panel data from 99 countries over the period 1975-2005 to indicate that the impact of urbanization on carbon emissions varied across the stages of development, and that further modernization might diminish this impact [12].

- Hu and Wang (2016) indicated that the growth of urbanization slowed down the growth in carbon emissions in China over the past 30 years [13].

- Zhang et al. (2013) indicated that there was an inverted U-shaped relationship between urbanization and carbon emissions from 1995 to 2011 [14]; and Martínez and Maruotti (2011) indicated that an inverted U-shaped relationship between urbanization and carbon emissions existed in developing countries over the period 1975-2005 [15].

With the growth of urbanization, both driving effects and inhibiting effects will change. Nevertheless, these studies examined the urbanization effect mainly from the perspective of time series. In fact, the urbanization effect, which is caused by each percentage point growth in urbanization, will also change $[9,16]$. Therefore, marginal utility theory is used to analyze the relationships between urbanization and carbon emissions.

The main methods used for research into urbanization effect on carbon emissions are the IPAT [17], STIRPAT [18-20], SDA [21-22], GTWR [23-25], co-integration analysis [9, 26-28], the Kuznets curve [14, 15], and panel data models [29-30]. Most recent studies of residents' consumption and carbon emissions used SDA to analyze the effects, such as those by Wang et al. (2016) [21] and Minx et al. (2011) [31]. Total emissions were always decomposed into population, energy intensity, GDP per capita, and carbon emissions coefficient using Kaya identity. Therefore, recent studies using Kaya identity always considered urbanization effect indirectly [10]. Owing to the short history of the publication of inputoutput tables in China and the long timescale involved, using the SDA method to analyze the resident consumption effect faces the problems of the study period being short and the relevant time interval long. This paper develops a modified version of the Kaya identity that incorporates urbanization and resident consumption. This method can consider urbanization directly and overcome some restrictions faced by some studies based on an inputoutput table. This method can examine different effects; however, this paper only considers the urbanization effect.

There are obvious differences in urbanization, resident consumption, energy consumption, and carbon emissions 
across the different regions within China [31-32]. Without a sufficient understanding of regional carbon emissions, it is difficult to implement national policies or strategies effectively and efficiently [33]. Jiangsu Province, which is a relatively developed area of China, is currently going through a period of rapid urbanization that has made the urban population grow rapidly during the past 20 years. Meanwhile, resident consumption, including that of both urban and rural residents, has also increased with the growth of urbanization and economic development. Besides, the total energy consumption of Jiangsu was 298 million tons of coal equivalent in 2014, and only Shandong Province consumed more energy than Jiangsu. Therefore, carbon reductions in Jiangsu will have an important influence on national carbon reductions. Promoting the urbanization process is still the principal development strategy of Jiangsu, and it is a major challenge for Jiangsu Province to reduce carbon emissions without impairing the growth in urbanization and economic development. Estimating the change in urbanization effect, caused by a growth in urbanization of $1 \%$, can better explain the relationship between urbanization and its effects, therefore, the concept of the marginal urbanization effect is introduced. This paper aims to find the inflection point at which the marginal urbanization effect will begin to decrease.

In comparison with current studies, the innovation and contribution of this paper lie in the following aspects. First, the extended Kaya identity incorporates urbanization and resident consumption, and it can consider urbanization directly and overcome certain restrictions faced by some studies based on input-output tables. Secondly, the concept of the marginal urbanization effect is introduced, which can better explain the relationship between urbanization and its effects. Thus, this paper aims to provide theoretical guidance for policymaking in Jiangsu.

\section{Material and Methods}

\section{Estimation of Energy-Related Carbon Emissions}

Energy-related carbon emissions were calculated using the formula given by the IPCC Guidelines for National Greenhouse Gas Inventories [35-37], which can be expressed as follows:

$$
C_{t}=\sum_{i} E_{i}^{t} \times E F_{i} \times C V_{i} \times O_{i}
$$

...where $C_{t}$ denotes the total energy-related carbon emissions in year $t$, subscript $i$ denotes the different fuels considered in this study ( $10^{6}$ tons), $E_{i}^{t}$ denotes the total energy consumption of fuel $i$ in year $t\left(10^{6}\right.$ tons, $\left.10^{8} \mathrm{~m}^{3}\right)$, $E F_{i}$ denotes the lower calorific value of fuel $i, C V_{i}$ denotes the carbon emissions factor of fuel $i$, and $O_{i}$ denotes the carbon emissions factors of fuel $i$. These coefficients are shown in Table 1.

\section{Urbanization Effect}

The Kaya identity [41] establishes a quantitative relationship between carbon emissions and various factors, including population, energy, and economic activity. The relevant equation is shown as follows:

Table 1. Conversion factors, lower calorific value (LCV), oxidation rate, and carbon emission factors of different fuel.

\begin{tabular}{|c|c|c|c|c|}
\hline Fuels & $\begin{array}{c}\text { Conversion factors }(\mathrm{t} \text { ce } / \mathrm{t} \\
\left.\text { or tce } / 10^{3} \mathrm{~m}^{3}\right)^{\mathrm{a}}\end{array}$ & $\begin{array}{c}\mathrm{LCV} \\
\left(\mathrm{MJ} / \mathrm{t} \text { or } \mathrm{MJ} / \mathrm{Mm}^{3}\right)^{\mathrm{b}}\end{array}$ & $\begin{array}{l}\text { Carbon emission factors } \\
(\mathrm{TC} / \mathrm{TJ})^{\mathrm{c}}\end{array}$ & Oxidation rate ${ }^{c}$ \\
\hline Raw coal & 0.714 & 20.908 & 25.8 & 0.918 \\
\hline Cleaned coal & 0.900 & 26.344 & 27.680 & 0.918 \\
\hline Other washed coal & 0.286 & 8.363 & 25.800 & 0.918 \\
\hline Coke & 0.971 & 28.435 & 29.410 & 0.928 \\
\hline Crude oil & 1.429 & 41.816 & 20.80 & 0.979 \\
\hline Gasoline & 1.471 & 43.070 & 18.900 & 0.986 \\
\hline Kerosene & 1.471 & 43.070 & 19.600 & 0.980 \\
\hline Diesel oil & 1.457 & 42.652 & 20.170 & 0.982 \\
\hline Fuel oil & 1.429 & 41.816 & 20.000 & 0.980 \\
\hline LPG & 1.714 & 50.179 & 17.200 & 0.990 \\
\hline Refinery gas & 1.571 & 46.055 & 18.200 & 0.989 \\
\hline $\begin{array}{l}\text { Other petroleum } \\
\text { products }\end{array}$ & 1.429 & 41.816 & 20.000 & 0.980 \\
\hline Gas & 1.330 & 38.931 & 17.200 & 0.990 \\
\hline
\end{tabular}

aata resource: [38]; ${ }^{b}$ Data resource: [39]; ${ }^{\mathrm{c}}$ Data resource: [40] 


$$
C=\frac{C}{E} \times \frac{E}{G D P} \times \frac{G D P}{P} \times P
$$

... where $C, E, G D P$, and $P$ denote total carbon emissions, total energy consumption, gross domestic product, and population, respectively. In order to study urbanization's effect on carbon emissions from the perspective of resident consumption, both rural and urban population and consumption should be included in the equation. The Kaya identity can be extended as follows:

$$
C=\frac{C}{E} \times \frac{E}{G D P} \times \frac{G D P}{C O N} \times \frac{C O N}{P} \times P
$$

...where CON denotes total resident consumption, which includes urban consumption (UCON) and rural consumption (RCON). $P U$ and $P R$ are used to denote the urban and rural populations, respectively. Total resident consumption can be expressed as follows:

$$
C O N=\left(\begin{array}{c}
\frac{U C O N}{P U} \\
\frac{R C O N}{P R}
\end{array}\right) \times\left(\begin{array}{cc}
\frac{P U}{P} & \frac{P R}{P}
\end{array}\right) \times P
$$

By merging equations (3) and (4) into one equation, both rural and urban population and consumption can be included, as in Equation (5).

$$
\begin{aligned}
& C=\frac{C}{E} \times \frac{E}{G D P} \times \frac{G D P}{C O N} \times\left(\begin{array}{c}
\frac{U C O N}{P U} \\
\frac{R C O N}{P R}
\end{array}\right) \times\left(\begin{array}{ll}
\frac{P U}{P} & \frac{P R}{P}
\end{array}\right) \times P \\
& =C E \times E G \times G C \times\left(\begin{array}{c}
U C P \\
R C P
\end{array}\right) \times\left(\begin{array}{ll}
P U P & P R P
\end{array}\right) \times P
\end{aligned}
$$

...where $C E=C / E$ denotes the carbon emissions coeffi-cient; $E G=E / G D P$ denotes energy intensity; $G C=G D P / C O N$ denotes the ratio of GDP to resident consumption, which is inversely proportional to the residents' consumption rate and reflects the relationship between $G D P$ and the residents' consumption rate; $U C P=U C O N / P U$ and $R C P=R C O N / P R$ reflect the per capita consumption of urban and rural residents, respectively; and finally, $P U P=P U / P$ and $P R P=P R / P$ reflect the proportions of the urban and rural populations, respectively.

Both sides of equation (5) first undergo logarithmic processing, and then processing using differential coefficients.

$$
\begin{gathered}
d \ln C=d \ln C E+d \ln E G+d \ln G C+ \\
+\frac{d(P U P \times U C P+P R P \times R C P)}{P U P \times U C P+P R P \times R C P}+d \ln P \\
=d \ln \left(C E \times E G \times G C \times P U P^{S U} \times P R P^{S R} \times\right. \\
\left.\times U C P^{S U} \times R C P^{S R} \times P\right)
\end{gathered}
$$

$\quad S U=\frac{P U P \times U C P}{P U P \times U C P+P R P \times R C P} \quad$ and
$S R=\frac{P R P \times R C P}{P U P \times U C P+P R P \times R C P}$ denote the proportions of urban and rural resident consumption, respectively. Therefore, in order to decompose the carbon emissions, Equation (5) can be rewritten as follows:

$C=C E \times E G \times G C \times P U P^{S U} \times P R P^{S R} \times U C P^{S U} \times R C P^{S R} \times P$

Energy-related carbon emissions can be decomposed into the contributions of different determinant factors. According to the logarithmic mean divisia index (LMDI) model, urbanization's effect $(\triangle C U)$ on carbon emissions from the perspective of resident consumption between the baseline year 0 and year $t$ can be expressed as follows:

$\Delta C U=\frac{C^{t}-C^{0}}{\ln C^{t}-\ln C^{0}} \times\left(\frac{\ln P U P^{S U^{t}}}{\ln P U P^{S U^{0}}}+\frac{\ln P R P^{S R^{t}}}{\ln P R P^{S R^{0}}}\right)$

It can be seen that the urbanization effect depends upon the proportions of the urban and rural populations and urban and rural resident consumption in this paper.

\section{Marginal Urbanization Effect}

Marginal utility theory examines the increase in satisfaction that is derived from consuming an extra unit of a good; however, the level of utility is not constant [4243]. Therefore, the marginal urbanization effect refers to the effect that is caused by each percentage point increase or decrease in urbanization, while other conditions remain unchanged. Therefore, the marginal urbanization effect can be expressed as follows:

$$
M C E=\frac{C U_{t}-C U_{0}}{U_{t}-U_{0}}=\frac{\Delta C U}{\Delta U}
$$

...where $C U_{t}$ and $C U_{0}$ denote the urbanization effect in years $t$ and 0 , respectively; $U_{t}$ and $U_{0}$ denote urbanization in years $t$ and 0 , respectively. 
Estimating the Relationship between Marginal Urbanization Effect and Urbanization

The Kuznets curve theory was introduced to estimate the relationship between the marginal urbanization effect and the rate of urbanization. The use of logarithmic processing can eliminate the influence of heteroscedasticity [44-45]. Therefore, on the basis of the Kuznets curve theory and typical studies $[15,46]$, the Kuznets curve model was established as follows:

$\ln M C E=\beta_{0}+\beta_{1} \ln U+\beta_{2}(\ln U)^{2}+\beta_{3}(\ln U)^{3}+\varepsilon$

$\ldots$ where $\beta_{0}, \beta_{1}, \beta_{2}$, and $\beta_{3}$ denote estimated parameter and $\varepsilon$ denotes random error. Different numerical values of $\beta_{0^{\prime}} \beta_{1}$, $\beta_{2}$, and $\beta_{3}$ can reflect the nature of the curve that describes the relationship between the marginal urbanization effect and urbanization. The curve describing the relationship may be linear with a positive or negative correlation, a U-shaped curve, an inverted U-shaped curve, an N-shaped curve, or an inverted $\mathrm{N}$-shaped curve.

\section{Data Sources}

In this paper, urbanization refers to the process of a population shift from rural to urban areas. The people living in urban areas will increase gradually. Therefore, this paper uses the proportion of urban people to represent urbanization.

The data of population and resident consumption is obtained from the Jiangsu Statistical Yearbook (19962015). Energy data includes all fuel types obtained from the Energy Balance Table by Region of the China Energy Statistical Yearbook (1996-2015). Data about resident consumption is taken in constant prices of 1995 in order to avoid the influence of inflation.

\section{Results and Discussion}

Process of the Evolution of Energy-Related Carbon Emissions and Urbanization

According to the results of calculations (Fig. 1), energy-related carbon emissions between 1995 and 2014 in Jiangsu exhibited an overall increasing trend. The total amount of carbon emissions increased from 68.84 million tons in 1995 to 250.31 million tons in 2014, which represents an increase by a factor of about 3.64 over a 20 -year period. The change in carbon emissions showed two stages. During the period 1995-2002, the average annual growth rate was only $1.32 \%$. During the period after 2002, carbon emissions increased much faster, albeit with fluctuations, from 80.41 million tons to 250.31 million tons, with an average annual growth rate of $10.91 \%$.

The rate of urbanization had been growing steadily. It grew from $27.30 \%$ in 1995 to $65.21 \%$ in 2014 , which

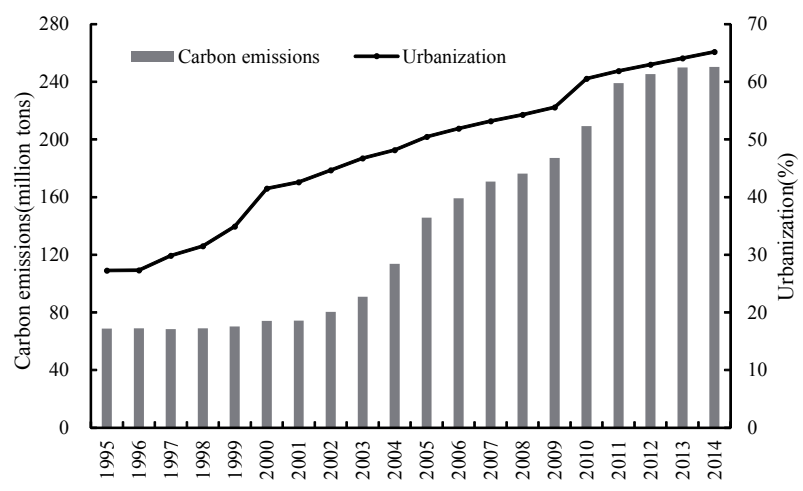

Fig. 1. The evolution process of energy-related carbon emissions and urbanization.

represents an increase by a factor of about 2.39 , with an average annual growth rate of $4.78 \%$. The urban population increased from 19.29 million in 1995 to 51.88 million in 2014; meanwhile, the rural population decreased from 51.36 million to 27.69 million. During this 20 -year period, resident consumption also grew rapidly, with a growth rate of $13.52 \%$. The per capita consumption of urban and rural residents increased by factors of 4.13 and 3.89, respectively, whereas the total consumption of residents in urban and rural areas increased by factors of 11.11 and 2.10 , respectively. Therefore, the total consumption of residents, in particular in urban areas, increased rapidly.

\section{Contribution of Urbanization to Carbon Emissions}

On the basis of the extended Kaya identity, using Equation (8), the total increase in emissions and urbanization effect were calculated as shown in Table 2. The total increase of 181.47 million tons between 1995 and 2014, and the total contribution of urbanization was 39.05 million tons, which accounted for $21.52 \%$ of the total. This illustrates that the evolution of urbanization was an important influencing factor that contributed to the increase in energy-related carbon emissions in Jiangsu. Therefore, the carbon emissions caused by the evolution of urbanization were huge; nevertheless, fluctuations were also large in different years (Fig. 2). As shown in Fig. 2, fluctuations in the urbanization effect and changes in the rate of urbanization were also similar.

During the process of urbanization the industrial structure changed constantly, which had a significant influence on energy consumption and carbon emissions. During the period 1995-2014, Jiangsu's economy developed rapidly, with a growth rate of $11.97 \%$, and the value of industrial output accounted for more than $40 \%$ of GDP during this period. Owing to the speed of economic and industrial development, the demand for high-carbon energy also increased rapidly. In the meantime, the proportion of tertiary industry was also increasing. Until 2014 , the value of tertiary industrial output was slightly less than the value of secondary industrial output. Although the energy consumption of tertiary industry was lower 
Table 2. Total effect and urbanization effect in Jiangsu from 1995 to 2014.

\begin{tabular}{|c|c|c|c|c|c|}
\hline Years & $\begin{array}{c}\text { Total effect } \\
(\Delta \mathrm{C}) / \text { million tons }\end{array}$ & $\begin{array}{l}\text { Urbanization effect } \\
(\Delta \mathrm{CU}) / \text { million tons }\end{array}$ & Years & $\begin{array}{c}\text { Total effect } \\
(\Delta \mathrm{C}) / \text { million tons }\end{array}$ & $\begin{array}{l}\text { Urbanization effect } \\
(\Delta \mathrm{CU}) / \text { million tons }\end{array}$ \\
\hline $1995-96$ & 0.150 & 0.01 & 2005-06 & 31.95 & 1.76 \\
\hline 1996-97 & -0.51 & 1.23 & 2006-07 & 13.61 & 1.69 \\
\hline $1997-98$ & 0.57 & 0.93 & 2007-08 & 11.56 & 1.50 \\
\hline 1998-99 & 1.18 & 2.13 & 2008-09 & 5.40 & 1.86 \\
\hline $1999-2000$ & 3.99 & 4.61 & $2009-10$ & 10.92 & 7.93 \\
\hline 2000-01 & 0.19 & 0.71 & 2010-11 & 22.15 & 2.17 \\
\hline 2001-02 & 6.02 & 1.41 & 2011-12 & 29.76 & 1.92 \\
\hline $2002-03$ & 10.55 & 1.63 & $2012-13$ & 6.27 & 1.88 \\
\hline 2003-04 & 22.77 & 1.26 & 2013-14 & 4.71 & 1.77 \\
\hline 2004-05 & 0.150 & 2.65 & Total & 181.47 & 39.05 \\
\hline
\end{tabular}

than that of secondary industry, the rapid development of tertiary industry could also promote energy consumption and energy-related carbon emissions [10, 47]. Therefore, owing to the process of urbanization together with rapid economic development and evolution of the industrial structure, Jiangsu's energy consumption and carbon emissions also increased.

The rapid growth in resident consumption had an influence on carbon emissions. There was considerable migration from rural areas to cities and towns during the process of urbanization. This migration also changed consumer demand, consumer behavior, and life-style of migrants, therefore these changes influenced energy consumption and carbon emissions. The influence of urbanization on resident consumption and energy-related carbon emissions mainly comprised three aspects:

1. Households could be partly self-sufficient in rural areas, but urban residents had to purchase necessities. Commercial production's demand for energy was much greater than that of self-sufficient rural households, and therefore the indirect energy consumption caused by residents' consumption of goods would also increase [48]. Furthermore, traditional forms of energy accounted for a significant proportion of the total in rural areas, whereas fossil energy was the main form of energy used in commercial production. Therefore, these all led to increases in energy-related carbon emissions.

2. The income of urban residents became relatively higher than that of rural residents during the evolution of urbanization in Jiangsu. The increase in income levels further stimulated residents' consumption, and energy consumption and carbon emissions also increased.

3. With the increase in income levels, living standards improved and the consumption structure also changed. In comparison to rural residents, urban residents' consumption goods generally had the characteristics of a large carbon footprint.

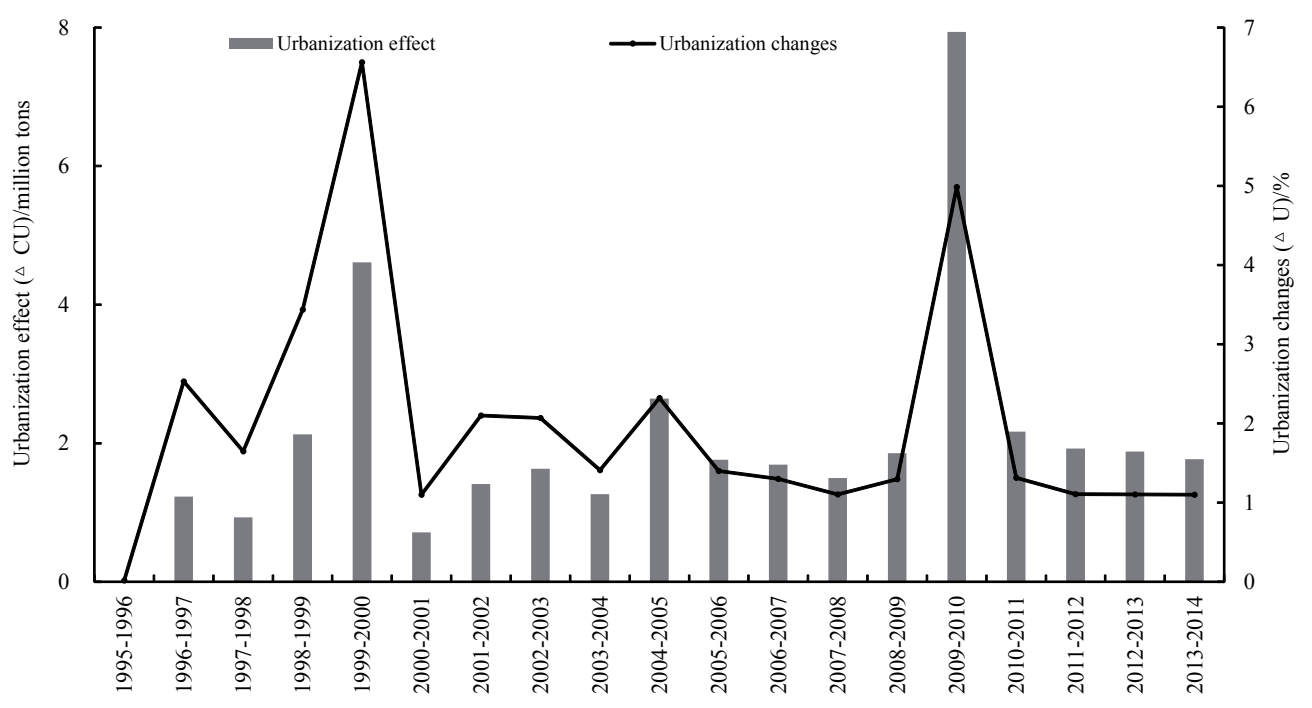

Fig. 2. Urbanization effect and urbanization changes from 1995 to 2014. 
Table 3. Marginal urbanization effect.

\begin{tabular}{|c|c|c|c|}
\hline Years & $\begin{array}{c}M C E \text { (Million } \\
\text { tons) }\end{array}$ & Years & $\begin{array}{c}\text { MCE (Million } \\
\text { tons) }\end{array}$ \\
\hline $1995-96$ & 0.530 & $2005-06$ & 1.258 \\
\hline $1996-97$ & 0.486 & $2006-07$ & 1.300 \\
\hline $1997-98$ & 0.564 & $2007-08$ & 1.362 \\
\hline $1998-99$ & 0.626 & $2008-09$ & 1.428 \\
\hline $1999-2000$ & 0.699 & $2009-10$ & 1.593 \\
\hline $2000-01$ & 0.650 & $2010-11$ & 1.641 \\
\hline $2001-02$ & 0.671 & $2011-12$ & 1.749 \\
\hline $2002-03$ & 0.788 & $2012-13$ & 1.692 \\
\hline $2003-04$ & 0.896 & $2013-14$ & 1.624 \\
\hline $2004-05$ & 1.140 & average & 1.089 \\
\hline
\end{tabular}

Besides, the evolution of urbanization promoted urban construction, which increased the demand for high-rise buildings and infrastructure. Therefore, the demand for energy-intensive raw materials such as cement increased. The increase in transport distances within urban areas also influenced energy-related carbon emissions.

\section{Marginal Urbanization Effect}

According to Equation (9) the marginal urbanization effect was calculated, as shown in Table 3. During the period of 1995-2014, the marginal urbanization effect exhibited an overall increasing trend and its contribution to emissions increased from 0.530 million tons in 1996 to 1.089 million tons in 2014, with an average growth rate of $6.42 \%$. As the average marginal urbanization effect is 1.089 million tons, this illustrated that the marginal carbon emissions caused by urbanization increased to 1.089 million tons when the rate of urbanization increased by $1 \%$, and also that their average growth rate was greater than the rate of growth in urbanization during this period. From Table 3 it can be seen that the change in the marginal urbanization effect showed two stages. During the period 1995-2004, the marginal urbanization effect was less than 1 million tons, which illustrated that the rate of growth in marginal urbanization effect was slower than the rate of growth in urbanization. During the period after 2004, the marginal urbanization effect was greater than 1 million tons, therefore it grew faster than the rate of urbanization.

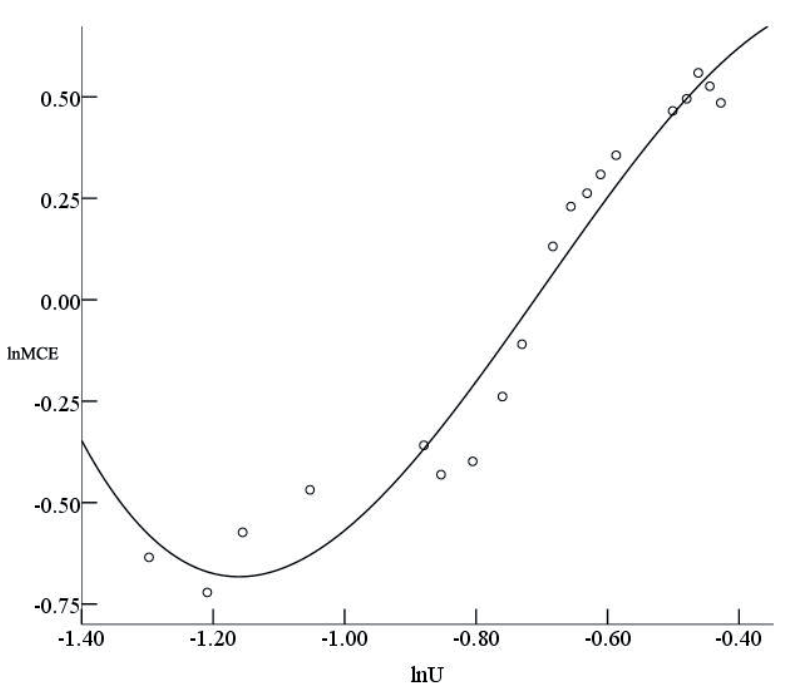

Fig. 3. Fit curve of marginal urbanization effect and urbanization.

\section{Relationship between the Marginal Urbanization Effect and the Rate of Urbanization}

In order to analyze the relationship between the marginal urbanization effect and the rate of urbanization, the Kuznets curve theory was used to test whether there existed a U-shaped curve, an inverted U-shaped curve, an $\mathrm{N}$-shaped curve, or an inverted $\mathrm{N}$-shaped curve. In order to eliminate the influence of heteroscedasticity, each variable needed to undergo logarithmic processing [44-45]. SPSS 16.0 statistical software was used to perform regression analysis, and the results are shown in Table 4.

It can be seen from Table 4 that the $\mathrm{R}^{2}$ value in type 3 is maximum, which illustrates that equation (13) $\left(\ln M C E=0.412-2.966 \ln U-7.548(\ln U)^{2}-3.602(\ln U)^{3}\right)$ can be effectively used to explain the relationship between these two variables, and the fitting curve is an inverted $\mathrm{N}$-shaped curve (Fig. 3). When $\ln U=-0.236$ or -1.160 (i.e., $U=78.94 \%$ or $31.33 \%$ ), the value of $\ln M C E$ reaches its extreme points. The marginal urbanization effect exhibits a decreasing trend until the urbanization rate reaches $33.13 \%$ and $78.94 \%$. When the urbanization rate is between $33.13 \%$ and $78.94 \%$, the marginal urbanization effect will increase with the growth of urbanization. The marginal urbanization effect will begin to decrease and the rate of urbanization will continue to grow, when the urbanization rate reaches $78.94 \%$. According to Planning of New-Type Urbanization and Integration of Urban-Rural Development (2014-20) in Jiangsu

Table 4. Kuznets curve estimation results of marginal urbanization effect and urbanization.

\begin{tabular}{|c|c|c|c|c|}
\hline Types & Equations & $\mathrm{R}^{2}$ & $\mathrm{~F}$ & Sig. \\
\hline Equation (11) & $\ln M C E=1.191+1.599 \ln U$ & 0.899 & 150.696 & 0.000 \\
\hline Equation (12) & $\ln M C E=2.113+4.062 \ln U+1.467(\ln U)^{2}$ & 0.945 & 137.776 & 0.000 \\
\hline Equation (13) & $\ln M C E=0.412-2.966 \ln U-7.548(\ln U)^{2}-3.602(\ln U)^{3}$ & 0.957 & 112.324 & 0.000 \\
\hline
\end{tabular}


Province and Urban System Planning of Jiangsu Province (2015-30), Jiangsu's urbanization rate will reach $72 \%$ in 2020 and $80 \%$ in 2030 . Therefore, the inflection point of the marginal urbanization effect will likely appear during the period 2020-30.

According to the trend in the marginal urbanization effect, it can illustrate that the urbanization effect caused by each $1 \%$ growth of urbanization will continue to increase until the inflection point, and will decrease only after the inflection point. In other words, when the urbanization rate reaches $78.94 \%$, the urbanization effect caused by each $1 \%$ growth in the rate of urbanization will decrease. Therefore, Jiangsu will still face the urgent situation of emission reductions during the process of urbanization.

\section{Discussion}

The Kaya identity has been used in different modified versions based on the different study perspective. In this paper, urbanization and resident consumption were incorporated directly into the extended Kaya identity. Therefore, this paper studied the urbanization effect by analyzing changes in the urban and rural population and resident consumption. In general, the rate of growth in urbanization will slow down when the urbanization rate is higher. For instance, if Jiangsu's urbanization rate reaches 80\% in 2030 in accordance with Urban System Planning of Jiangsu Province (2015-30), the average growth rate is only $1.29 \%$ from 2014 to 2030 , whereas the average growth rate was $4.69 \%$ from 1995 to 2014 . The urbanization effect may increase more slowly or decrease because of the decrease in the growth rate with time. Therefore, the marginal urbanization effect can better reflect the change in urbanization effect with each $1 \%$ growth in the rate of urbanization. It can also reflect the quality of urbanization to some extent. Jiangsu Province is a relatively developed area of China, and its urbanization rate is also relatively high. However, the marginal urbanization effect will still increase, and Jiangsu will still face the urgent situation of emission reductions during the process of urbanization. Therefore, Jiangsu should also pay attention to the urbanization effect even though it may increase slowly or decrease, and the results of this paper on marginal urbanization effect make it clear that controlling carbon emissions without impairing the growth in urbanization and economic development is still a major challenge for Jiangsu Province. Besides, this study on Jiangsu Province can also provide a new approach for other or less developed areas that are in the process of rapid urbanization.

During the process of urbanization, economic activities, the industrial structure, lifestyles, the demand for transportation, and spatial distributions will all change, and these changes will influence carbon emissions. Therefore, urbanization's effect on carbon emissions involves not only environmental problems but also complex socioeconomic problems. Future studies on the urbanization effect need to combine different disciplines such as demography, sociology, economics, and geography.

\section{Conclusions and Policy Recommendations}

This paper analyzed the urbanization effect on energyrelated carbon emissions from the perspective of resident consumption using an extended version of the Kaya identity, the LMDI model, marginal utility theory, and the Kuznets curve theory. Some conclusions were drawn as follows:

1. Energy-related carbon emissions from 1995 to 2014 in Jiangsu exhibited an overall increasing trend. The change of carbon emissions showed two stages. After 2002 carbon emissions increased much faster, whereas urbanization had been increasing steadily, and resident consumption had also grown rapidly.

2. The carbon emissions caused by the evolution of urbanization were very high, nevertheless, fluctuations were also large in different years. The fluctuations in the urbanization effect and changes in the rate of urbanization were similar. During the process of urbanization, the industrial structure, lifestyles, the demand for transportation, spatial distributions, and so on will all change, and these changes will influence carbon emissions.

3. The marginal urbanization effect exhibited an overall increasing trend. The change in the marginal urbanization effect showed two stages. During the period 1995-2004, growth in the marginal urbanization effect was slower than the growth in the rate of urbanization. During the period after 2004, the marginal urbanization effect grew faster than the rate of urbanization.

4. The marginal urbanization effect will begin to decrease, but the rate of urbanization will continue to grow when the urbanization rate reaches $78.94 \%$. The inflection point will be likely to appear during the period 2020-30. When the rate of urbanization reaches $78.94 \%$, the urbanization effect caused by each $1 \%$ growth in the rate of urbanization will also decrease.

In light of the above-mentioned findings, some policy implications are proposed:

1. Attention needs to be paid to the quality of the development of urbanization. According to the abovementioned findings, the effect of urbanization caused by each $1 \%$ growth in the rate of urbanization begins to decrease only after the urbanization rate reaches $78.94 \%$. Jiangsu therefore needs to use innovative ideas to promote the development of urbanization. According to the Ministry of Education, Jiangsu ranks first in the number of universities that are located in the province and can take advantage of their innovations. Jiangsu should also employ these advantages to promote its scientific and technological innovation in low-carbon technology and the adjustment of its industrial structure, lifestyles, and structure of energy consumption, which will all promote the quality of the development of urbanization.

2. Highly energy-intensive enterprises should be eliminated, and industries with low energy consumption and high added value should be given 
priority in development. Besides, the carbon emissions of construction and its related industries should not be ignored. Green building technologies should be popularized, and research into low-carbon materials should be strengthened. During the future progress of urbanization science and technology will be very helpful for upgrading the pattern of development and structural transformation of the economy.

3. During the process of urbanization attention should be paid to improving urban residents' quality of life and encouraging low-carbon consumption patterns. With the growth of urbanization, tens of millions of rural residents have become urban residents. Meanwhile, economic development and the growth in living standards have changed residents consumption patterns. Therefore, during the process of urbanization attention should be paid to carbon emissions caused by resident consumption, in particular by urban residents. Therefore, the government needs to encourage the public toward low-carbon consumption such as buying energy-conserving products and automobiles powered by new energy sources.

4. Currently, coal is still the major source of energy in Jiangsu. Optimizing the structure of energy consumption and improving energy efficiency are very important for Jiangsu for controlling its carbon emissions. The consumption of wind energy and other forms of clean energy should be increased, and the consumption of coal should be controlled. Low-carbon technology should be developed to improve energy efficiency.

\section{Acknowledgements}

The current work is supported by the National Natural Science Foundation of China (Nos. 41371518 and 41501144) and Scientific Research Innovation Projects of Graduate Students in Jiangsu Province (No. KYLX16_1272).

\section{References}

1. IPCC. Climate change 2007:Synthesis Report. Contribution of Working Groups I, II and III to the Fourth Assessment Report of the Intergovernmental Panel on Climate Change [Core Writing Team, Pachauri, R.K and Reisinger, A. (eds.)]. IPCC, Geneva, Switzerland, 104, 2007.

2. QIU J. China's climate target: is it achievable?. Nature, $\mathbf{4 6 2}$ (7273), 550, 2009.

3. DAVID M. China's peak carbon pledge raises pointed questions. Science, 346 (6212), 903, 2014.

4. MUNEER T., CELIK A. N., CALISKAN N. Sustainable transport solution for a medium-sized town in Turkey - A case study. Sustainable Cities and Society, 1 (1), 29, 2011.

5. MADLENER R., SUNAK Y..Impacts of urbanization on urban structures and energy demand: What can we learn for urban energy planning and urbanization management? Sustainable Cities and Society, 1 (1), 45, 2011.

6. DONGLAN Z., DEQUN Z., PENG Z. Driving forces of residential $\mathrm{CO}_{2}$ emissions in urban and rural China: An index decomposition analysis. Energy Policy, 38 (7), 3377, 2010.

7. COLE M. A., NEUMAYER E. Examining the impact of demographic factors on air pollution. Population and Environment, 26 (1), 5, 2004.

8. YORK R. Demographic trends and energy consumption in European Union Nations, 1960-2025. Social Science Research, 36 (3), 855, 2007.

9. WANG Y., CHEN L., KUBOTA J. The relationship between urbanization, energy use and carbon emissions: evidence from a panel of Association of Southeast Asian Nations (ASEAN) countries. Journal of Cleaner Production, 112, 1368, 2016.9.

10. WU Y., SHEN J., ZHANG X. The impact of urbanization on carbon emissions in developing countries: a Chinese study based on the U-Kaya method. Journal of Cleaner Production, 135, 589, 2016.

11. FAN Y., LIU L., C., WU G., WEI Y.M. Analyzing impact factors of $\mathrm{CO}_{2}$ emissions using the STIRPAT model. Environmental Impact Assessment Review, 26 (4), 377, 2006.

12. POUMANYVONG P., KANEKO S. Does urbanization lead to less energy use and lower $\mathrm{CO} 2$ emissions? A crosscountry analysis. Ecological Economics, 70 (2), 434, 2010.

13. HU L., WANG J.F. Analysis of the long term impact of carbon dioxide emissions and short term fluctuation effect of urbanization in China. Journal of Arid Land Resources and Environment, 30 (8), 97, 2016 [In Chinese].

14. ZHANG H.W., WANG K.Y., XIANG B.W. Research on different impacts of urbanization on $\mathrm{CO}_{2}$ emissions. China Population, Resources and Environment, 23 (3), 152, 2013 [In Chinese].

15. MART N.I., MARUOTTI A. The impact of urbanization on $\mathrm{CO}_{2}$ emissions: Evidence from developing countries. Ecological Economics, 70 (7), 1344, 2011.

16. ZHANG L.Q. Impact limit of urbanization evolution on carbon emission in Anhui Province based on combined model. Journal of Natural Resources, 30, 152, 2015 [In Chinese].

17. DIETZ T., ROSA E.A. Effects of population and affluence on $\mathrm{CO}_{2}$ emissions. Proceedings of the National Academy of Sciences of the United States of America, 94 (1), 175, 1997.

18. WANG Y., ZHANG X., KUBOTA J. ZHU X., LU G. A semi-parametric panel data analysis on the urbanizationcarbon emissions nexus for OECD countries. Renewable and Sustainable Energy Reviews, 48,704, 2015.

19. LI K., LIN B. Impacts of urbanization and industrialization on energy consumption $/ \mathrm{CO}_{2}$ emissions: Does the level of development matter? Renewable and Sustainable Energy Reviews, 52, 1107, 2015.

20. HAN J., MENG X., ZHOU X., YI B.L., LIU M., XIANG W.N. A long-term analysis of urbanization process, landscape change, and carbon sources and sinks: A case study in China>s Yangtze River Delta region. Journal of Cleaner Production, 141, 1040, 2017.

21. WANG Z., YANG Y. Features and influencing factors of carbon emissions indicators in the perspective of residential consumption: Evidence from Beijing, China. Ecological Indicators, 61, 634, 2016.

22. FENG K., HUBACEK K. Carbon implications of China's urbanization. Energy, Ecology and Environment, 1 (1), 39, 2016.

23. WANG S.J., FANG C.L., MA H.T., WANG Y., QIN J. Spatial differences and multi-mechanism of carbon footprint based on GWR model in provincial China. Journal of Geographical Sciences, 24, 612, 2014. 
24. LIU Y., CHEN Z.M., XIAO H.W., YANG W., LIU D.H., CHEN B. Driving factors of carbon dioxide emissions in China: an empirical study using 2006-2010 provincial data. Frontiers of Earth Science, 1, 2016.

25. HY Y.X., PAN J.H., LI Z., BAI Y., ZHANG J.H. Spatialtemporal analysis of provincial carbon emissions in China from 1997 to 2012 with EOF and GWR methods. Acta Scientiae Circumstantiate, 36 (5), 1866, 2016 [In Chinese].

26. LIU Y., YAN B., ZHOU Y. Urbanization, economic growth, and carbon dioxide emissions in China: A panel cointegration and causality analysis. Journal of Geographical Sciences, 26 (2), 131, 2015.

27. BAEK J. A panel cointegration analysis of $\mathrm{CO}_{2}$ emissions, nuclear energy and income in major nuclear generating countries. Applied Energy, 145, 133, 2015.

28. AHMAD A., ZHAO Y., SHAHBAZ M. Carbon emissions, energy consumption and economic growth: An aggregate and disaggregate analysis of the Indian economy. Energy Policy, 96, 131, 2016.

29. ZHANG C., LIN Y. Panel estimation for urbanization, energy consumption and $\mathrm{CO}_{2}$ emissions: A regional analysis in China. Energy Policy. 49, 488, 2012.

30. LIDDLE B., LUNG S. Might electricity consumption cause urbanization instead? Evidence from heterogeneous panel long-run causality tests. Global Environmental Change. 24, 42,2014

31. MINX J.C., BAIOCCHI G., PETERS G.P.A "carbonizing dragon": China's fast growing $\mathrm{CO}_{2}$ emissions revisited. Environ Sci Technol, 45 (21), 9144, 2011.

32. ZHANG Y.X., WANG H.K., SAI L., XU M., LIU W.D., LI S.L., ZHANG R.R., P. NIELSEN C., BI J. Temporal and spatial variations in consumption-based carbon dioxide emissions in China. Renewable and Sustainable Energy Reviews, 40, 60, 2014.

33. WANG C.J., ZHANG X.L., WANG F., LEI J., ZHANG L. Decomposition of energy-related carbon emissions in Xinjiang and relative mitigation policy recommendations. Frontiers in Earth Science, 9 (1), 65, 2015.

34. LIU Z., GUAN D., MOORE S., LEE H., SU J., ZHANG Q. Steps to China's carbon peak. Nature, 522 (7556), 271, 2015.

35. WANG Y., XIE T., YANG S. Carbon emission and its decoupling research of transportation in Jiangsu Province. Journal of Cleaner Production, 142 (20), 907, 2016,

36. WANG C., WANG F., ZHANG X. Examining the driving factors of energy related carbon emissions using the extended
STIRPAT model based on IPAT identity in Xinjiang. Renewable and Sustainable Energy Reviews, 67, 51, 2017.

37. WANG Q, GAO Z, NING J. Model-based assessment of the pattern differences and the equity of national carbon emissions in China during 2000-2010. Journal of Cleaner Production, 103, 696, 2015.

38. LIANG S., ZHANG T. What is driving $\mathrm{CO}_{2}$ emissions in a typical manufacturing center of South China? The case of Jiangsu Province. Energy Policy, 39 (11), 7078, 2011.

39. XI F., GENG Y., CHEN X. Contributing to local policy making on GHG emission reduction through inventorying and attribution: A case study of Shenyang, China. Energy Policy, 39 (10), 5999, 2010.

40. GENG Y., ZHAO H., LIU Z. Exploring driving factors of energy-related $\mathrm{CO} 2$ emissions in Chinese provinces: A case of Liaoning. Energy Policy, 60, 820, 2013.

41. Y K. Paris: Presentation to the Energy and Industry Subgroup, Response Strategies Working Group, IPCC, 1989.

42. WANG H.M. My views concerning Marginal Utility. Journal of Huaqiao University (philosophy and social science edition), 2, 1, 2011 [In Chinese].

43. KAUDER E. Metaphysicians of economics. (Book Reviews: A History of Marginal Utility Theory). Science, 151,1377, 1966.

44. ZHANG L., GAO J. Exploring the effects of international tourism on China's economic growth, energy consumption and environmental pollution: Evidence from a regional panel analysis. Renewable and Sustainable Energy Reviews, 53, 225, 2016.

45. WANG P., WU W., ZHU B., WEI Y. Examining the impact factors of energy-related $\mathrm{CO}_{2}$ emissions using the STIRPAT model in Guangdong Province, China. Applied Energy, 106, 65, 2013.

46. WANG Y., ZHANG C., LU A., LI L., HE Y.M., TOJO J., ZHU X.D. A disaggregated analysis of the environmental Kuznets curve for industrial $\mathrm{CO}_{2}$ emissions in China. Applied Energy, 190, 172, 2017.

47. WU Y.Z., SHEN J.H., ZHANG X.L., SKITMORE M., LU W.S. The impact of urbanization on carbon emissions in developing countries: a Chinese study based on the U-Kaya method. Journal of Cleaner Production, 135, 589, 2016.

48. CLANCY J., MADUKA O., LUMAMPAO F. Chapter 24-Sustainable Energy Systems and the Urban Poor: Nigeria, Brazil, and the Philippines. Urban Energy Transition, 533$562,2008$. 